\title{
O Mundo em Que Vivi e Rio sem Ponte de Ilse Losa: entre História e ficção
}

\author{
Ana Cristina Vasconcelos de Macedo \\ Instituto Politécnico do Porto \\ https://orcid.org/0000-0002-1377-4422
}

[Recibido, 26 setembro 2020; aceptado, 9 novembro 2020]

[Vasconcelos de Macedo, A. C. (2020). O Mundo em Que Vivi e Rio sem Ponte de llse Losa: entre História e ficção. Boletín Galego de Literatura, 57, "Notas", 17-29]

DOI http://dx.doi.org/10.15304/bgl.57.7133

RESUMO Neste artigo, procede-se à análise dos romances portugueses de llse Losa O Mundo em Que Vivi, editado em 2019, pela Hércules de Ediciones, em galego e em castelhano, e Rio sem Ponte, a ser brevemente publicado nos dois idiomas pela mesma editora, do ponto de vista do diálogo entre literatura e História. Estes romances tematizam questões relacionadas com o exílio e o Holocausto, tendo sido preocupação da Autora não deixar esquecer o passado histórico, apelando ao questionamento da História e à equidade no julgamento desses mesmos factos históricos.

PALABRAS CHAVE: Ilse Losa; memória histórica; nacional-socialismo.

ABSTRACT In this article, we analyze the Portuguese novels by llse Losa O Mundo em Que Vivi, published in 2019 by Hércules de Ediciones in Galician and Spanish, and Rio sem Ponte, soon to be published in both languages by the same publisher, from the point of view of the dialogue between literature and history. These novels deal with issues related to exile and the Holocaust, and it was the author's concern not to forget the historical past, appealing to the questioning of history and equity in the judgment of these same historical facts.

KEYWORDS: Ilse Losa; historical memory; National Socialism.

Isso foi apenas um prelúdio, lá onde se queimam livros, um dia também se queimarão pessoas.

Réplica de Hassan a Almansor ${ }^{1}$

O Mundo em que Vivi, publicado em Portugal no ano de 1949 por Ilse Losa e recentemente traduzido para galego e para castelhano e editado pela Hercules de Edicións, juntamente com Rio sem Ponte, de 1952, e brevemen-

1 Almansor, tragédia escrita em 1821 pelo poeta Heinrich Heine (1969, p. 852). No original: "Hassan: Das war ein Vorspiel nur, dort wo man Bücher / Verbrennt, verbrennt man auch am Ende Menschen" (Capítulo II). 
te publicado em galego e castelhano pela mesma editora de A Coruña, são dois romances que revelam literariamente circunstâncias e ocorrências que marcam a entrada na história do genocídio nazi e, por conseguinte, se constroem pela interseção de tempos e de espaços historicamente datados. Este cruzamento de datas e de acontecimentos históricos com sequências espáciotemporais ficcionalizadas autoriza a leitura destas obras enquanto romances de testemunho, no que se refere a uma possível função sociológica da literatura, sem, contudo, descuidarmos a necessária atenção para os desvios de linguagem impostos pelos códigos do sistema modelizante secundário - a transgressividade do sistema literário tem por fim a representação da corrente de consciência das personagens e a representação de realidades por elas experienciadas e não a mimetização, através de processos de descrição e de análise, nem a verificação dessas mesmas realidades ao nível da factualidade histórica. Nestes dois romances, a interseção dos planos ficcional e factual processa-se, pois, através da enunciação discursiva, sendo que é na enunciação que se inscreve esta dupla temporalidade.

Desta forma, O Mundo em que Vivi e Rio sem Ponte inserem-se no que podemos chamar uma "exilliteratur", ou seja, um corpus de obras escritas por autores que voluntária ou involuntariamente abandonaram a Alemanha, após o incêndio de Reichstag, ocorrido a 27 de fevereiro de 1933, e também os países anexados no curso da Segunda Guerra Mundial.

Ilse Lieblich Losa é uma escritora que, neste processo migratório, se insere na categoria ${ }^{2}$ dos cidadãos judeus ou de ascendência judia comuns que, pela sua condição étnica, foram obrigados ao autoexílio, na medida em que inicia a carreira de escritora depois de se ter fixado na cidade do Porto, no norte de Portugal, em 1934. Com a publicação de O Mundo em que Vivi, e, do ponto de vista da matéria histórica, a Autora ficcionalizou / tematizou questões relacionadas com o exílio e o Holocausto, tendo sido sua preocupação não deixar esquecer o passado histórico, apelando ao questionamento da História e à equidade no julgamento desses mesmos factos históricos.

2 Consideramos, na primeira categoria de exilados, os intelectuais alemães (judeus ou não) que ideológica e politicamente se opunham ao regime nacional-socialista. Entre estes, encontram-se os escritores Stefan Zweig, Klaus Mann, Thomas Mann e Heinrich Mann, Bertolt Brecht, Hermann Broch, Anna Seghers e os filósofos Walter Benjamin, Georg Lukács, Theodor Adorno e Ernst Bloch, para só referir alguns. 
No vasto conjunto da obra de Ilse Losa, O Mundo em que Vivi, Rio sem Ponte e Sob Céus Estranhos (1962) foram os únicos romances que escreveu, afastando-se, posteriormente, deste género narrativo e dedicando-se mormente à escrita para crianças e jovens. No universo da escrita para adultos, lembramos, a propósito desta tematização do exílio e do ajustamento ao país de chegada, os contos de Histórias quase Esquecidas (1950), os poemas em prosa de Grades Brancas (1951), alguns dos contos breves de Aqui Havia uma Casa (1955), os de Encontro no Outono (1964) e também os textos breves de O Barco Afundado (1979).

Quando nos referimos ao conceito de memória aplicada à literatura alemã do pós-guerra, estudiosos da área da sociologia estabeleceram uma tipologia de quatro formatos de memória - individual, social, política e cultural. No entanto, e não obstante a explosão de interesses sobre a literatura entre duas Guerras, mais particularmente a que surgiu depois da II Grande Guerra Mundial - tomada por alguns como documentos que registam eventos e sucessos históricos -, já na Grécia Antiga existia uma disciplina que visava trabalhar e desenvolver a arte da memória através de técnicas mnemónicas que possibilitavam a representação e a transmissão do conhecimento histórico e cultural. Deve-se ao poeta Simonides Melicus, e depois a Cícero e a Quintiliano, o desenvolvimento destas técnicas de recolha e registo de imagens culturais que deram origem a narrativas explicativas do lugar do homem no mundo e da ordenação do mundo pelo homem. Para além disto, diz-nos Renate Lachmann (2008, p. 302),

Preservar a memória cultural envolve algo como um aparato de memória através da duplicação, ou seja, da representação do ausente por meio da imagem (phantasma ou simulacrum), da coisificação da memória (como poder e habilidade, como um espaço de consciência, ou como um thesaurus), e da prevenção do esquecimento através da recuperação de imagens (a recuperação constante do sentido perdido). ${ }^{3}$

Assim, os textos resultantes da combinação de testemunhos empíricos transformados pela imaginação literária, ou seja, vertidos em imagens /representações desses eventos vividos constituem-se "bancos de memória" histórica e cultural.

3 Tradução minha. 
Esta arte de fixação da memória absorve e (res)semantiza textos da história oficial, dando aos leitores uma visão individual - a do autor textual e a das personagens que ficcionalmente interpretam certa visão do mundo e que, de forma particular, nele se posicionam, sem, contudo, anular certo grau referencial, antes potencializando semanticamente esta relação.

O Mundo em Que Vivi (1949) e Rio sem Ponte (1952) inserem-se na dimensão da Vergangenheitsbewältigung (saber lidar com o passado), ou seja, em ambos os romances deparamo-nos com a tentativa de analisar friamente os factos históricos e de compreender o que podemos chamar de uma "culpa coletiva" relativamente ao Holocausto. De resto, esta tendência é uma constante na obra da Autora - no conto "Encontro de outono", inserido no livro homónimo, a narradora encontra-se com antigas colegas do Liceu Schiller e, ao mesmo tempo que revivem tempos felizes da juventude, trocam pontos de vista sobre o Holocausto. Este diálogo entre amigas determina os sentidos da história e, desta forma, ficção e História autoinscrevem-se no espaço textual, fundindo, por via da interseção, os horizontes do texto e do leitor (Ricoeur, 1983, p. 120). Nos contos “A tília”, inserido em Encontro no Outono (1964), posteriormente adaptado para crianças sob o título A Estranha História de uma Tília (1981) e em "Apesar de tudo", incluído no livro Histórias Quase Esquecidas (1950), também reescrito para crianças e publicado em A Minha Melhor História (1985), a recuperação da memória histórica e a representação ficcional das perseguições nazis, a fuga do país de origem e a chegada a países estranhos e consequente reajustamento do eu são linhas de força que obrigam os leitores a revisitar criticamente ou a conhecer as histórias particulares que compõem a História da Europa entre as duas Grandes Guerras.

Em O Mundo em Que Vivit, as vivências/experiências/emoções da narradora autodiegética Rose Frankfurter inscrevem-se numa moldura espácio-temporal que vai de 1913 - da data do seu nascimento - a 1933, momento em que Hitler é nomeado chanceler do III Reich e se vê obrigada a abandonar a Alemanha, com aproximadamente vinte anos de idade. No entanto, o enunciado mobiliza e fixa determinadas datas nesse longo arco temporal em que a história se inscreve. Nesta ordem de ideias, a data de 1914 será a pri-

4 Para uma leitura mais aprofundada de $O$ Mundo em que Vivi do ponto de vista de questões relacionadas com os conceitos de crossover fiction e de literatura autobiográfica ver o estudo A Escrita de llse Losa para a Infância, publicado em 2018. 
meira a ser memorizada por Rose: "Não me lembrava do tio Franz, porque só tinha um ano quando fora mobilizado. Isso acontecera, aliás, no ano de 1914, segundo me explicava o avô. Um ano importante, o de 1914, que viria a ser registado no livro de História” (Losa, 2009, p. 22).

As localizações temporais das ações são determinadas, na maior parte das vezes, por inferências que o leitor terá de fazer a partir dos factos históricos mencionados pela narradora.

De certa forma, a obra poderá ser dividida em partes que corresponderão a uma tomada de consciência crescente, por parte de Rose Frankfurter, desses momentos históricos. Numa primeira parte, que corresponde à primeira infância passada em casa dos avós paternos, Rose, através de uma focalização condicionada pelo seu olhar de criança, ou seja, de quem apenas percebe o lado maravilhoso dos factos históricos que entrecortadamente ouve dos adultos, como acontece com a sua representação do Kaiser Guillherme II ("Eu ouvira alguém dizer que a flor favorita do Kaiser era o miosótis. Por isso imaginava o Kaiser num castelo azul, numa sala forrada de papel azul, com mobília de pelúcia azul, mas sem cobertas brancas a tapá-la, sentado no trono azul, segurando na mão um raminho de miosótis. E precisamente por causa desse raminho eu não conseguia associar o kaiser a guerras e carnificinas. Miosótis e morte estavam um para o outro como a cor branca para a preta" (Losa, 2009, p. 26). Esta imagem do Kaiser como um príncipe perfeito, à semelhança dos contos de fadas, dissipar-se-á numa conversa entre Rose e o avô Markus. Da mesma forma, o fim da I Guerra é um acontecimento de que Rose não esquecera e que regista.

À medida que a antipatia pelos judeus começa a produzir efeitos persecutórios sobre as personagens, o olhar inocente de Rose sobre o mundo começa a diluir-se e a desmoronar-se ao longo da narrativa, como peças de um dominó. Da mesma forma, no processo de leitura, o leitor empírico toma consciência crítica sobre as realidades sociais e políticas reveladas pelo tecido ficcional e, com isso, a obra alcança o objetivo pedagógico de oferecer elementos que dão a conhecer e/ou favorecem a compreensão dos factos históricos vividos em primeira pessoa e de permitir uma reflexão e consequente reposicionamento face a acontecimentos marcantes da História da Europa e do Mundo, como o Holocausto e as Guerras, contribuindo, assim, para uma postura de resistência às ideologias totalitárias e de recusa da xenofobia. As 
palavras de Mário Dionísio, que transcrevo, são reveladoras deste efeito de leitura:

É natural que O mundo em que vivi continue a ser para mim (amores de juventude) a sua obra preferida. Pela surpresa que causou. Pelo muito que nos disse, e nessa altura, do país onde o nazismo (tão próximo do nosso poder político de então) barbaramente imperava. Pelo tal afecto que se instalou nas nossas vidas. Trinta e nove anos depois, há passos dessa obra que mantenho frescos na memória. (Dionísio, 1988, p. 14)

No panorama editorial português, o romance Rio sem Ponte é, tal como $O$ Mundo em Que Vivi, bem recebido pelos leitores e pela crítica literária, tendo sido classificado nos paratextos editoriais como "uma genuína obra de arte literária” (Amorim, 1952, p. 7).

Os eventos diegéticos que compõem a história quotidiana e privada das personagens de Rio sem Ponte são narrados ulteriormente por uma voz heterodiegética que nos fornece elementos para inferir que a ação se localiza no início de 1932 e é protagonizada por dois jovens de dezasseis anos de idade.

A ação organiza-se em duas partes espácio-temporalmente bem definidas, e que determinam uma mudança da ação, e centra-se, ao contrário de $O$ Mundo em Que Vivi, em duas personagens alemãs não judias - Johann Schuster e Jutta Berner -, assumindo, a primeira, papel de relevo na primeira parte da obra e, a segunda, a centralidade na segunda parte. Resumidamente, este romance narra a vida de dois adolescentes de dezasseis anos, Johann e Jutta, que se apaixonam. Por dificuldades económicas, Jutta e a mãe abandonaram a cidade W., localizada na região do Ruhr, e instalaram-se em R.. Nesta cidade, conhece Johann, filho de Bernhard Schuster, dono de uma loja de tecidos, e de Ellen Schuster, que não sobreviveu ao parto de Johann.

Na primeira parte da obra, que termina em dezembro de 1932, assistimos à procura de emprego por parte dos dois jovens que, por motivos decorrentes da Grande Depressão ou Crise [económica] de 1929, não puderam continuar os estudos - Johann é admitido como aprendiz nos armazéns de tecidos Hoehler \& Bernstein e Jutta como secretária na fábrica de estampilhas para decoração Druckemann. 
Se, em algumas situações o recurso ao dispositivo da história oficial é direto, na maior parte das vezes é insinuado, o que exige a implicação do leitor, através da pesquisa e mobilização do conhecimento histórico por forma a ser possível uma leitura cabal das várias camadas de significação / intencionalidade inscritas nos enunciados literários. Vejamos, com exemplos retirados da obra, como se operacionaliza literariamente esta mobilização de conhecimentos oriundos não só do campo da História, mas também da Simbologia e dos estudos bíblicos, e respetiva consequência interpretativa ou efeito de leitura: a primeira parte da narrativa de Rio sem Ponte termina, como referi no parágrafo anterior, em dezembro de 1931: “estava-se em Dezembro, no mês em que nascera o menino Jesus que, dizia-se, trouxera a salvação e o amor aos homens. Crianças erguiam os rostos para escutar o doce conto de Belém, enquanto a macia luz das velas se reflectia nos seus olhos espantados" (Losa, 1988, p. 63). Este capítulo termina com toda uma descrição de aparente ambiente de serenidade imposto pela quadra natalícia. No entanto, no capítulo imediatamente a seguir, assistimos ao anúncio de encerramento da fábrica de Druckemann e ao despedimento de Jutta Berner, e das suas colegas de trabalho, num país que "tem seis milhões de desempregados" (Losa, 1988, p. 65), o que determinará a sua partida para Londres.

Estes últimos capítulos da primeira parte, retratam a atmosfera política, económica e social dos primeiros meses de 1932. Se, à data dos eventos ficcionais, o país apresentava $30 \%$ de taxa de desemprego, esse valor subiria, em 1933, para uma taxa superior a 44\%. A revisitação dos factos reais e da carga simbólico-religiosa de que se reveste a época natalícia espessará a circularidade da célula dramática e permitirá ao leitor associar-se, de forma consciente e indagadora, ao universo narrado e suas múltiplas intencionalidades, apropriando-se deliberadamente do texto e posicionando-se face aos factos históricos.

Na segunda parte de Rio sem Ponte, e na sequência da empresa ter aberto falência, Jutta parte para Londres, em 1932, onde toma conta de crianças, em regime de au pair, em casa da família Finkelberg, de ascendência judia. Para trás fica a Alemanha, a família, os amigos e, especialmente, Johann.

A narração dos eventos diegéticos desta segunda parte intercala-se com a troca de correspondência entre Johann e Jutta. Esta enunciação epistolar privada vai assumir funções diversas na leitura global da intriga e, ao mes- 
mo tempo, vai adquirir particular importância nos quase dois anos que Jutta passa em Londres. Por um lado, é através desta comunicação deferida que se mantém a relação afetiva entre as duas personagens, agora fisicamente separadas, mas é também por via das cartas recebidas que Jutta se reanima identitariamente - não só através da língua materna alemã, mas também pela revisitação da memória afetiva dos espaços onde fora feliz com Johann, dos amigos e família, em particular do tio Georg e da mãe. Por isso, Jutta pede a Johann, na segunda carta, depois de ter confessado sentir-se "como que metida numa gaiola que só se abre às quintas-feiras, às 2 da tarde, e também, de quinze em quinze dias, aos domingos" (Losa, 1988, p. 119),

Escreve-me muito, muito! Todos os dias, ao acordar, espero que chegue uma carta tua. [...] Diz o que fazes e o que pensas, e se pensas em mim e porque é que pensas em mim, e muito mais coisas das que gosto de saber. Mas podes também falar-me das que não gosto de saber!

Ao contrário de Londres, espaço anónimo e de desenraizamento, para Jutta, as cartas constituem-se espaço de memória, de desejo e de ancoragem, e, paradoxalmente, é pelas cartas que ganha forma a dimensão dramática do exílio e da errância da personagem naquele país estranho e culturalmente tão diferente do seu onde se sente desprotegida e perdida.

No entanto, e a par desta função interna à diegese, a correspondência trocada por ambos é também um espaço especular da relação entre a literatura e a História, na medida em que, sendo ficcionais, apresentam um duplo destinatário (intratextual), que as recebe e as lê, e o leitor empírico, criando-se, assim, um duplo efeito de real.

Em Londres, quase não se fala da Alemanha e as pessoas com quem Jutta vive raramente se interessam pela sua história de vida. Ao longo desta segunda parte, sinaliza-se apenas o momento em que Sam Finkelberg lê em voz alta a notícia de que Hitler fora nomeado chanceler da Alemanha. Apesar de serem uma família de origem polaca judia, a notícia não lhes despertou grande preocupação - Sam Finkelberg limita-se a fazer um pequeno comentário sobre o antissemitismo e sua mulher, Lea, acrescenta que esse assunto nada tem a ver com eles, desvalorizando a informação. Apenas Mamma se revela preocupada com a ideia de um programa alemão de perseguição aos judeus que pudesse chegar a Inglaterra: "Quem nos garante a nós que a desgraça não pegue também aqui? Para fazer mal toda a gente está pronta num instante. 
Que dizes, Sam? / - Não, Mamma, não vamos tão longe. O nosso Governo não consentiria" (Losa, 1988, p. 131). Não satisfeita com a resposta do genro, pede aclarações a Jutta e esta "contou-lhes que havia bastante tempo que os nazis, de uniforme castanho, andavam por toda a parte a fazer comícios e distúrbios" (Losa, 1988, p. 132), no entanto, era também da opinião de que talvez não fossem capazes de fazer mal aos judeus, apesar de saber, pelas cartas de Johann, da existência de situações desagradáveis entre empregados judeus e adeptos do nacional-socialismo nazis, nos armazéns Hoehler \& Bernstein, onde Johann trabalha.

Dias após esta conversa, Jutta recebe nova carta de Johann, descrevendo a atitude das pessoas logo após a tomada de posse de Hitler:

Deves ter lido que nos jornais que Hitler foi nomeado chanceler do Reich. Não calculas o que aqui se passou. Milhares de pessoas uniformizadas marcharam, ainda na mesma noite, pelas ruas, com archotes na mão. Gritavam: Sieg Heil e, embriagadas de alegria, cantavam estranhos hinos ${ }^{5}$. Nunca cá se viu tal coisa. Assisti na Osterstrasse, no meio da multidão. Muitas pessoas erguiam os braços, mas outras estavam como eu, com cara aborrecida e espantada. Já sabes que não aprecio os nazis. Nunca encontrei um único que me agradasse. [...] O ambiente na cidade e no armazém torna-se-me de dia para dia mais desagradável. [...] P. S. - O que dizem os ingleses do nosso novo chanceler?. (Losa, 1988, pp. 132-134)

Este duplo ato de comunicação ficcional por carta, que privilegia a relação entre aquele que se exprime, o destinatário e o codestinatário, que é o leitor empírico, como já referi, proporciona aquela experiência humana inscrita na linguagem de que falava Émile Benveniste em O Homem na Linguagem (1976), dispondo o leitor para uma certa relação ética com o mundo e favorecendo uma espécie de (re)semantização dos referentes históricos.

A vida de Jutta, em Londres, passa devagar entre lides domésticas cansativas e rotineiras que pouco tempo lhe deixam para pensar na Alemanha - de

5 Nota minha: Horst Wessel Lied, ou Die Fahne Hoch, seria provavelmente um desses estranhos hinos. Esta marcha foi composta por Horst Ludwig Wessel, adepto do nacional-socialismo e membro da polícia paramilitar de Hitler, para as SA, tornando-se, depois hino do Partido Nazi. Após a proclamação de Hitler, o hino oficial da Alemanha passou a ser o Horst Wessel Lied a que foi acrescentada a primeira estrofe de "Das Lied der Deutschen" (1841), poema escrito por Heinrich Hoffmann para a melodia do Gott erhalte Franz den Kaiser (1797), também conhecido como Kaiserhymne (quarteto de cordas em dó, Op. 76,3) composta por Haydn. Wessel foi assassinado, em janeiro de 1930, por dois elementos do Partido Comunista Alemão (KPD), tornando-se mártir e símbolo maior da propaganda nacional-socialista. 
resto, o afastamento do seu país, em 1932, não lhe permitiu ter consciência da gravidade dos acontecimentos nem das proporções da(s) política(s) de Hitler.

Mais tarde, no dia 1 de abril, Sam Finkelberg chega a casa com vários jornais contendo notícias sobre os acontecimentos recentes na Alemanha e cuja leitura em voz alta deixa Jutta em sobressalto e com um sentimento de culpa por não estar presente a apoiar Johann:

Boicotagem de casas comerciais na Alemanha. Às 3 horas da tarde do dia 1 de Abril todos os empregados e empresas judaicas têm de abandonar os seus postos e fazer uma demonstração de protesto contra a agitação internacional judaica. Fotógrafos estarão nas ruas para filmar as pessoas que se atreverem a entrar em lojas de judeus, e projectar-se-ão os filmes em todos os cinemas. (Losa, 1988, p. 140)

Os mesmo jornais, dias depois, davam conta da reação de Londres em relação a essas ocorrências sob a forma "um meeting de protesto, na Whitechapel Art Gallery" e através de um telegrama enviado à Alemanha por "um tal de Lord Snowden, afirmando a sua repulsa por tais cruéis acontecimentos" (Losa, 1988, p. 141). Nesta passagem, torna-se relevante atentarmos na (intencional) utilização da expressão "um tal de", a respeito dessa personagem da história da Inglaterra ficcionalmente evocada, na medida em que esta expressão indefinida, a somar a flexão do verbo dizer na terceira pessoa do plural no pretérito imperfeito, formulação também ela impessoal e indefinida, revela um aparente desconhecimento do narrador sobre esta pessoa, impulsionando o leitor competente a procurar nos textos historiográficos quem foi essa figura que se posicionou contra estes atos - os primeiros de uma série de medidas mais violentas que se seguiriam contra a comunidade judaica, como, por exemplo, a Lei da Restauração do Serviço Civil Profissional promulgada uma semana após este boicote, em 7 de abril.

A ausência de correspondência por parte de Johann certificando a veracidade das notícias, leva Jutta a convencer-se de que "aquilo não passava de 'histórias de jornais"” (Losa, 1988, p. 141), firmando-se, assim, a infactividade semântica inerente à fórmula verbal na expressão "diziam também os jornais".

Marcada por uma elipse temporal cujas balizas surgem indeterminadas textualmente, a antepenúltima carta de Johann é enviada a partir da Suíça. 
Johann ainda se encontra na Alemanha, mas o agravamento das medidas contra os judeus e opositores ao regime de Hitler tornam perigosa a troca de correspondência, pelo que a personagem é obrigada a servir-se de um amigo como intermediário. Nessa carta, Johann pede a Jutta que tenha cuidado com o que escreve. Conta também que o tio de Jutta, Georg, anda fugido da polícia e que é necessário dinheiro para que permaneça escondido. Nessa mesma carta, Johann confirma as notícias que Jutta lera nos jornais londrinos e descreve a "limpeza" que os agentes das SA fizeram às lojas judias, incluindo os armazéns do Bernstein onde trabalhava. Com a precipitação dos acontecimentos, Jutta abandona a casa dos Finkelberg e vai trabalhar para casa do casal Trotter, onde será mais bem paga e poderá, assim, enviar o dinheiro necessário para proteger Georg.

Na penúltima carta, Jutta fica a saber que alguém denunciara o seu tio Georg e que este fora morto. O leitor será depois informado pela narradora - Jutta - que o seu próprio pai foi o denunciante.

A narrativa encerra-se com a última carta escrita por Johann e enviada de Berna, a 12 de novembro de 1934, onde agora se encontra. Fora também ele obrigado a fugir devido à sua amizade com Georg e por tê-lo mantido escondido em sua casa. Apesar da abertura do final, sabe-se que Johann teria ido ter com Jutta a Londres e que o regresso de ambos à Alemanha ficou adiado, na paradoxal esperança e incerteza dos dias porvir: "Nada planearam ao certo. Talvez ficassem aqui. Talvez seguissem para outra terra. Talvez. Talvez..." (Losa, 1988, p. 177).

Em O Mundo em que Vivi e em Rio sem Ponte, o diálogo entre a literatura e a História reveste-se de particular importância, na medida em que, através do olhar sobre o passado feito pelas instâncias narradoras / personagens, o leitor poderá questionar o presente em que vive e a inerente condição humana e construir o futuro que deseja para si e para os outros, preenchendo, como referiu Boucheron (2010, p. 169) os "silêncios crivados" nas narrativas oficiais.

A virtuosidade das narrativas de Ilse Losa que tematizam as perseguições nazis e a fuga para o exílio reside na extraordinária capacidade de as vozes enunciadoras do discurso não tomarem partido nem pelas vítimas nem pelos algozes, dando liberdade ao leitor para aderir ou não ao universo narrado. $\mathrm{E}$ essa margem de liberdade encontramo-la em O Mundo em que Vivi, através 
de uma personagem de ascendência judia que cresce e que assiste à fragmentação do seu núcleo vivencial (da família aos amigos), provocada por circunstâncias historicamente datadas, lamentando a condição humana, mas não expressando o ódio por aqueles que, na infância, foram seus amigos e que, com o advento do nacional-socialismo, se alistaram quer nas SA quer nas SS; em Rio sem Ponte, a perspetiva sobre os mesmos acontecimentos históricos é dada pelos olhos de duas personagens principais (e seu núcleo de amizades) não judias que em nada se identificam com aqueles que ajudaram a escrever as páginas ignominiosas da Europa do século XX. Também em "Esperança", conto inserido no livro Histórias Quase Esquecidas (1950), e mais tarde reescrito para crianças com o sugestivo título "Apesar de tudo" e publicado em A Minha Melhor História (1979), Marta, uma mulher cujo marido foi levado pelas forças nazis, viu-se obrigada a fugir com o filho pequeno e a refugiarse num país estrangeiro onde se confronta com a existência de um vizinho alemão pertencente às SS. No dia de anos de seu filho, este insistiu em convidar precisamente o filho desse homem que Marta tanto odiava e que era seu amigo. Durante a festa, Marta, depois de alguma perturbação, pergunta a si mesma: "Aquela criança, tem ela alguma culpa? [...] Não tem o mundo, a vida, que continuar? E não são estas crianças, que aí saltam e riem, a vida, o futuro? Aquele rapaz crescerá. E porque não há-de ser diferente do pai? De ter até vergonha do pai? De fazer por que as ideias do pai não vinguem mais?” (Losa, 1950, p. 100).

Estas histórias de Guerra, de perseguições e de perdas são também, e acima de tudo, narrativas de perdão e de esperança na humanidade e no futuro, de reflexão sobre os factos históricos. Os leitores transformam-se eles próprios em testemunhos do absurdo e, por conseguinte, responsáveis por recusar, ou não, a ordem totalitária em que emergem as matérias tratadas nestes romances.

\section{Bibliografia}

Amorim, G. (1952). Rio sem Ponte - Romance de Ilse Losa. O Século Ilustrado, p. 7.

Benveniste, É. (1976). O Homem na Linguagem. Ensaios sobre a instituição do sujeito através da fala e da escrita. Editora Arcádia.

Boucheron, P. (2010). Faire Profession d'Historien. Publications de la Sorbonne. 
Dionísio, M. (1988). Uma alemã portuguesa ou vice-versa. Letras \& Letras, p. 14.

Lachmann, R. (2008). Mnemonic and Intertextual Aspects of Literature. En H. von Astrid Erll e A. Nünning, Cultural Memory Studies. An International and Interdisciplinary Handbook (pp. 301-310). Walter de Gruyter.

Losa, I. (1950). Histórias Quase Esquecidas. Marânus.

Losa, I. (1964). Encontro no Outono. Marânus.

Losa, I. (1979). A Minba Melhor História. Editora Nova Crítica.

Losa, I. (1981). A Estranha História de uma Tília. Livros Horizonte.

Losa, I. (1988). Rio sem Ponte. Afrontamento.

Losa, I. (2009). O Mundo em Que Vivi. Afrontamento.

Ricoeur, P. (1987). Individu et identité personnell. En P. Veyne e J.-P. Vernant, L. Dumont, P. Ricoeur, F. Dolto, F. J. Varela, e G. Percheron (Colabs.), Sur l'Individu (pp. 54-72). Seuil. 